\title{
Knowledge and practices of nursing professionals in caring for ostomates
}

\author{
Saberes e práticas dos profissionais de enfermagem no cuidado às pessoas com estoma intestinal \\ Conocimientos y prácticas de profesionales en enfermería en el cuidado de personas con estoma intestinal
}

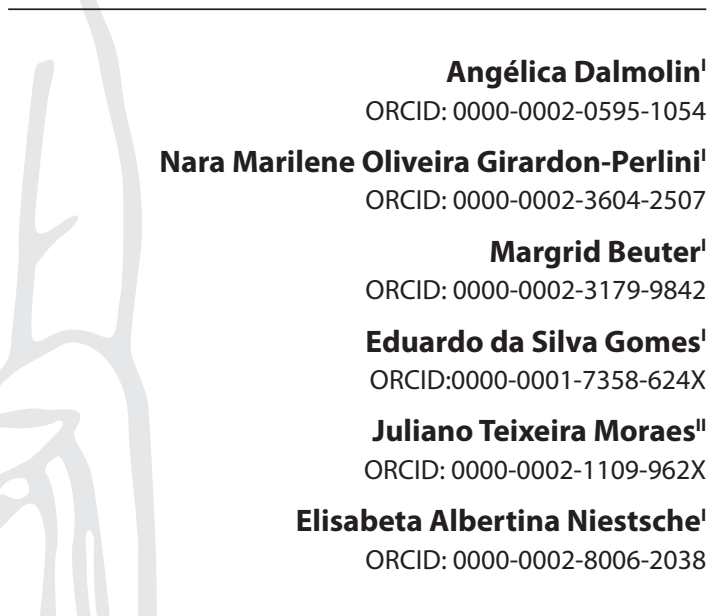

'Universidade Federal de Santa Maria. Santa Maria, Rio Grande do Sul, Brazil.

"Universidade Federal de São João del-Rei. São João del-Rei,

Minas Gerais, Brazil

How to cite this article:

Dalmolin A, Girardon-Perlini NMO, Beuter M, Gomes ES, Moraes JT, Niestche EA. Knowledge and practices of nursing professionals in caring for ostomates.

Rev Bras Enferm. 2020;73(Suppl 5):e20200018. doi: http://dx.doi.org/10.1590/0034-7167-2020-0018

\section{Corresponding author:} Angélica Dalmolin E-mail: angelica_dalmolin@hotmail.com

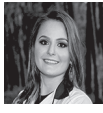

EDITOR IN CHIEF: Antonio José de Almeida Filho ASSOCIATE EDITOR: Priscilla Broca

Submission: 03-19-2020

Approval: 06-10-2020

\section{ABSTRACT}

Objective: to analyze the knowledge and practices of nursing professionals in caring for people with colostomy bag. Method: a qualitative and descriptive study conducted with 21 nursing professionals from a General Surgery Unit. Data collection used triangulation of techniques, based on non-participant observation, analysis of nursing records, and semistructured interviews. Analysis followed the spiral technique assumptions. Results: it was possible to comprehend the theoretical and scientific knowledge that subsidize practice; identify contradictions related to statement and care in the profession's daily work and the intervening factors, which can facilitate and/or make the nursing care process difficult. Final considerations: knowledge and practices of professionals in caring for ostomates occur within work experiences, in which socialization of knowledge makes it possible to expand the perspectives of care.

Descriptors: Ostomy; Surgical Stomas; Nursing Care; Nurse Practitioners; Nursing.

\section{RESUMO}

Objetivo: analisar os saberes e práticas dos profissionais de enfermagem no cuidado às pessoas com estoma intestinal de eliminação. Método: estudo qualitativo, descritivo, realizado com 21 profissionais de enfermagem de uma Unidade de Cirurgia Geral. A coleta de dados utilizou a triangulação de técnicas, a partir da observação não participante, análise dos registros de enfermagem e entrevista semiestruturada. A análise seguiu os pressupostos da técnica de espiral. Resultados: foi possível apreender os conhecimentos teóricos e científicos que subsidiam as práticas, identificar contradições relacionadas ao discurso e ao cuidado no cotidiano laboral da profissão, bem como os fatores intervenientes, os quais podem facilitar e/ou dificultar o processo de cuidar da enfermagem. Considerações finais: os saberes e práticas dos profissionais no cuidado às pessoas com estoma ocorrem no contexto das vivências e experiências laborais, em que a socialização do conhecimento possibilita ampliar as perspectivas de cuidado.

Descritores: Estomia; Estomas Cirúrgicos; Cuidados de Enfermagem; Profissionais de Enfermagem; Enfermagem.

\section{RESUMEN}

Objetivo: analizar el conocimiento y las prácticas de los profesionales de enfermería en el cuidado de las personas con estoma de eliminación intestinal. Método: estudio cualitativo, descriptivo, realizado con 21 profesionales de enfermería de una Unidad de Cirugía General. La recopilación de datos utilizó la triangulación de técnicas, basadas en la observación no participante, el análisis de los registros de enfermería y las entrevistas semiestructuradas. El análisis siguió los supuestos de la técnica espiral. Resultados: fue posible comprender los conocimientos teóricos y científicos que respaldan las prácticas, identificar contradicciones relacionadas con el discurso y la atención en el trabajo diario de la profesión, así como los factores intervinientes, que pueden facilitar y / o dificultar el proceso de atención de enfermería. Consideraciones finales: el conocimiento y las prácticas de los profesionales en el cuidado de personas con estoma se producen en el contexto de experiencias y experiencias laborales, en las que la socialización del conocimiento permite ampliar las perspectivas de la atención. Descriptores: Estomía; Estomas Quirúrgicos; Atención de Enfermería; Enfermeras Practicantes; Enfermería. 


\section{INTRODUCTION}

Nursing is the professionalization of care, resulting from the acquisition of scientific knowledge and technical skills that constitute its existential genesis, allowing to share actions, ideas and experiences in caring. Nursing care presupposes a comprehensive view, with a view to promotion, prevention and rehabilitation, seeking to value basic human needs and achieve balance in the biopsychosocial sphere ${ }^{(1)}$.

Therefore, nursing needs to transcend the technical work related to health-disease, bringing people who care and the beings who are cared for closer together, as it constitutes an encounter of subjectivities that enables a bond of trust and commitment ${ }^{(2)}$. Humanization of care is the product of technical activities, scientific knowledge and the expressive involvement of professionals in care actions and interpersonal relationships present in this process ${ }^{(1)}$.

In order to care for people who experience ostomy, it is essential that they be guided by a holistic view that contemplates humanism in care actions and consider the specificities necessary for their adaptation and rehabilitation ${ }^{(3)}$. Therefore, it is intended to emphasize the essence of care as an interactive process, which adds to the technical and scientific aspects and constitutes the knowledge and practices that guide the profession.

It is understood that studies related to caring for ostomates are recurrent in national and international literature; however, there is a need, from our insertion within care, to reiterate investigations related to nursing knowledge and practices, given the difficulties still perceived in caring for these people.

Ostomy consists of intervention for the construction of the stoma, which refers to the mouth or opening a hole that allows the communication of a hollow organ with the external environment. Ostomy is commonly performed in the intestine or bladder, when there is a need to divert effluent elimination. It is a procedure that contributes to the survival of patients, being performed as a therapy for different pathologies that affect the gastrointestinal and urinary tract ${ }^{(4)}$.

Nursing care for patients who experience the adversities of the repercussions of the stoma, regardless of the pre-surgical or postoperative phase, is complex. It involves care that needs to be initiated at the time of diagnosis and subsequent surgical indication. In this phase, nursing care aims to reduce fears, desires and the various doubts emerging in this period, favoring adaptation and autonomy ${ }^{(5-6)}$. Thus, care must include, in addition to aspects related to body and stoma care, social support and emotional support actions, with a view to overcoming the technical activities that guide nursing care, resulting in factors that enhance coping with difficulties that may arise ${ }^{(7)}$.

Theoretical-scientific knowledge on this theme becomes relevant to implement appropriate care practices, contributing to the strengthening of nursing as a science of care. Bearing this in mind, it is essential to know the nursing care for people with colostomy bag, in order to identify the knowledge and practices that constitute professional practice with this population.

Aiming to know the gaps in scientific production on the subject, a review was carried out in the theses and dissertations catalog of the Coordination for the Improvement of Higher Education Personnel (Coordenação de Aperfeiçoamento de Pessoal de Nível Superior, abbreviated CAPES). The following search strategy was carried out in order to identify and characterize the trend of Brazilian production regarding nursing care for ostomates: estomia OR estoma OR ostomia OR ostoma OR colostomia OR ileostomia.

In this search, it was identified that the studies carried out tend to address the perception of nursing professionals about care; explore aspects related to the role of people with a stoma and their family for self-care and care. The studies did not delve into the particularities and specificities of nursing practice in caring for this population. Thus, there is a gap related to scientific and practical knowledge of nursing professionals, which can be a factor that weakens care, postpones acceptance and adaptation to the new reality and reflects negatively on quality of life.

Knowing the experience of nursing professionals with this population will allow understanding of nursing work practices and comprehending the actions, knowledge, skills and difficulties encountered in caring for this population. Identifying the intervening factors will allow contextualization about how care is performed, corroborating the strengthening of nursing knowledge and practices. Given the above, the question is: what are the knowledge and practices of nursing professionals in caring for people with colostomy bag?

\section{OBJECTIVE}

To analyze the knowledge and practices of nursing professionals in caring for people with colostomy bag.

\section{METHODS}

\section{Ethical aspects}

This research is part of a dissertation developed in the Graduate Program in Nursing at Universidade Federal de Santa Maria (UFSM). The study respected the ethical precepts of Resolution 466/2012 of the Brazilian National Research Ethics Committee, being approved by the Research Ethics Committee. For anonymity of participants, alphanumeric codes (N1, N2, N3...) were used for nurses and (NT1, NT2, NT3...) for nursing technicians.

\section{Type of study}

This is a qualitative and descriptive study presented according to the Consolidated Criteria for Reporting Qualitative Research (COREQ) recommendations.

\section{Methodological procedures}

\section{Study setting and data source}

This study was carried out in a General Surgery Unit (GSU) at a university hospital in southern Brazil. The sector's nursing team is composed of 17 nurses and 37 nursing technicians, totaling 54 professionals. The study participants comprised 21 nursing professionals, 13 technicians and eight nurses from different work shifts. The definition of the number of participants followed the logic of relationship regarding the achievement of the objectives and the answer to the research question, having been interrupted as soon as it was reached. Nursing professionals in direct care for ostomates, with at least three months of experience in the GSU, a period that allows the routines of the sector to be acclimated, 
were included in the study. Professionals on vacation or on leave of any nature during the data collection period were excluded. There was a refusal to participate in the study.

\section{Collection and organization of data}

For data collection, we used triangulation of techniques of nonparticipant observation, analysis of nursing records in the patient's medical record, and semi-structured interview, from March to June 2018. This process was carried out by a graduate student, with the help of two scientific initiation fellows, who were previously trained through meetings to socialize the objectives of the study as well as approximation to the instruments for data collection.

Initially, patients were located in the pre- and postoperative period through nursing reports for making the stoma. Afterwards, the professionals who were assigned to direct care for these people were identified, according to the scale of distribution of personnel and work shifts, inviting them to participate in the study. The participants were informed about the objectives and the ethical aspects that guide research with human beings; and, upon acceptance, they signed the Informed Consent Form.

The non-participant observation stage was guided by a script elaborated based on the objectives of the study, which allowed to record in detail the observations made about the investigated object such as care, educational guidelines, family participation, among others. To record what was observed, in addition to the items proposed in the script, field diary was used, in which narratives and reflective notes were prepared. This phase took place over a period of 21 days, totaling 126 hours.

The second stage of data collection proceeded with analysis of nursing records in the medical records of ostomates. This step was guided by a script previously prepared to obtain information related to nursing care in assistance, management, and educational spheres. Thus, records, developments and data related to Systematization of Nursing Care (SNC) were analyzed.

The third stage sought, through semi-structured interview, to explore the subjective aspects of the participants' experiences regarding nursing care for people with colostomy bag. Moreover, it sought to complement, clarify and include information that was not accessed by non-participant observation and document analysis techniques. To that end, a script was used based on the following guiding question: how do you (participant name), from your work experiences, perceive the nursing care provided to people with colostomy bag? The interviews, conducted only once, took place in a room for health education activities in the sector, ensuring a quiet, private and free from interruptions. They were previously scheduled, conducted by a graduate student, individually, with an average duration of 40 minutes, being audio recorded and then transcribed in full. The interviews did not undergo a validation process by the participants. As a form of feedback to the participants, the research report was made available at GSU to be accessed by professionals, and the main results were discussed with the nurse in charge.

\section{Analysis of data}

Analysis was conducted following the data analysis spiral technique assumptions ${ }^{(8)}$, which requires analytical movements that allow advancing in a circular way in the understanding of the studied phenomenon. This technique was operationalized from data organization, reading and reminder, description, classification and interpretation in codes and themes.

The first round of data analysis spiral comprises organization of data. At that time, the material produced was systematized in files on the computer and converted into text units, to facilitate database organization and material exploration ${ }^{(8)}$. The units prepared were related to data from non-participant observation, records in field diary, medical records, and semi-structured interview.

The second loop of spiral consists of the reading step to explore the data after organization. It was possible to go deeper into the details that compose them, aiming to assist the interpretation of information through repetitive readings ${ }^{(8)}$. Also, reminders of short phrases, keywords, ideas and central concepts were written in order to guide the subsequent analysis process. Then, description, classification and interpretation of data in codes and themes evolved ${ }^{(8)}$. Coding allowed separating the text into themes, i.e., in broad groups of information, which aggregate different codes to form and strengthen a common idea.

Thus, 35 codes were organized, which were marked and grouped according to similarity of senses, initiating the formation of the themes. After new immersion and appropriation, they were reorganized into five themes, which make up the corpus of interpretive analysis, namely: Nursing knowledge: theoretical and scientific basis for care; Nursing care practices for people with colostomy bag; Between what is said and what is done: contradiction in nursing practice; Potentials/facilities in caring for ostomates; and Difficulties/weaknesses and their impact on nursing care.

Interpretation sought to make sense of the data, abstracting itself beyond codes and themes, in order to understand the findings. In this study, interpretation was carried out from the theoretical appropriation about the theme, being based on scientific literature.

\section{RESULTS}

Eight nurses and 13 nursing technicians participated in the study. Of these, 17 were female and four were male. The age range ranged from 26 to 57 years old. Regarding work characteristics, ten professionals worked in the morning, eight in the afternoon and three at night. The length of training ranged from three to 35 years, and the length of experience in the unit corresponded, for one of the participants, less than one year of service; 15 worked between one to five years; three worked for six to 15 years; and two had been working for over 20 years. Of the eight nurses participating in the study, five held master's degree and three were PhD. It should be noted that none had specialization in stomatherapy.

The results enabled the organization of five themes that explain the knowledge and practices of professionals in caring for people with colostomy bag.

\section{Nursing knowledge: theoretical and scientific basis for care}

Aspects related to knowledge for ostomate care were learned within care practice, with teaching and learning mediated by the exchange of experiences among professionals. 
I really went to experience, make changes, care and guidance here. The little I know I learned in practice. We had theorical basis, but, in practice, it is quite different. (N2)

I do not have experiences of much that I learned during my undergraduate course on ostomy. It is seen from above. There was not much depth on these issues. Welearn even on a daily basis with practice. (N8)

I didn't even know what a bag stuck to the patient's belly was like. And then there was a colleague who explained to me. (NT13)

It is evident, from the participants'statements, that the acquisition of knowledge during the professional training phase is directed, above all, to the theoretical focus, which is later complemented during practical experiences of care in hospitals. They emphasize that these are favored by the meeting with ostomates and their needs, and by the exchange of knowledge among professionals, as for installing and exchanging colostomy bags. Furthermore, professionals report having theoretical knowledge acquired during training, which often differs from practice.

In addition to the possibility of sharing knowledge among co-workers, the participants have the support of the institution's Study Group on Skin Injuries (Grupo de Estudos em Lesões de Pele, abbreviated GELP). Thus, when situations of difficult resolution arise or when professionals, in general, share the same doubts and concerns, GELP is called upon to carry out consultancies and training/sector updates. These opportunities are reported as valid, instructive and important as they make it possible to answer persistent questions and add new knowledge.

We always try to do some training, because there are GELP people and whenever possible, trainings are made with them. (N4)

Professionals recognize that, because they work in a place where patients are pre and postoperative for stoma-making surgeries, it is essential that they develop theoretical and practical knowledge to care for these people. Thus, they seek to clarify their difficulties by resorting to reading about the products to take care of stomas by searching the Internet and taking a specialization course.

I try to study about the products for ostomies in internet research and about things that I think are necessary, besides the graduate course in dermatology that I'm taking. (N5)

I study at home about the surgeries we usually see here and what care is needed, how is the procedure, how would recovery be. (NT2)

However, it became evident that during the work practice course, professionals recognize that there is some accommodation in the search for updating and theoretical knowledge from nursing literature, leading to a decrease in the study routine.

Currently, l acquire knowledge through training. Being graduated, we slightly reduce the theoretical search in literature. (N3)

In this context, it appears that the knowledge regarding stoma care comes, above all, from the work experiences in the GSU, in which cooperation among team allows for developing skills and collective growth.

\section{Nursing care practices for people with colostomy bag}

Nursing practice is centered, especially, in the postoperative period, exposing limitations related to the performance of the nursing team in other moments. During the observation stage, it was found that the professionals monitored directed attention and care, mainly activities related to emptying and cleaning the colostomy bag. Reinforcing the aspects observed, the professionals verbalized, during the interview, care actions, emphasizing care practice.

Discharge everything, leave it very clean. If you see the bag is very dirty, if it's taking off, then change it. (NT12)

I first discharge the feces inside and wash it well, then dry it well and clamp it when it doesn't have to be changed. (NT7)

Care is taken more for the bag hygiene, which we dump and sometimes, in some situation, we change. That's basically it. (NT4)

Registry in medical records reveal that the nursing team consists of professionals with different levels of knowledge about the care they provide; revealed by the discrepancy between very detailed records that depict the situation of patients and stoma; and, at the same time, incomplete records that do not explain the reality and that can make assessment, planning and continuity of care for ostomates difficult.

It was possible to identify, from triangulation of the collected data, that the care routine is centered, above all, on the performance of nursing technicians. They develop care demands related to stoma hygiene, emptying, cleaning and exchange of colostomy bag in the postoperative period.

Stoma care is carried out by the technical team, who perform all the care, washing, bag exchange, but do not provide guidance. Nurses, when they visit, assess the stoma, characteristics and whenever they have any difficulties, they give all assistance. (N7)

In the aspects presented, the social division of nursing work is evident. Nurses are in charge of assessing, planning and supervising care, in order to assist whenever necessary in the most complex demands, or, through complications established during technical assistance in carrying out care. Corroborating the above, analysis of medical records allows identifying the scarcity of records related to nursing evolution, given the insertion of nurses in management of care, which sometimes restricts their visibility in assisting these people.

In the nurses'statements, it is possible to verify that the activities developed by them in caring for ostomates are associated with supervision and guidance to other members of the nursing team. Thus, they offer support and attention in the most complex care situations.

The main care is done by the technicians. Nurses carry out supervision and guidance as requested. They assess and give special attention when they start changing the bag a lot, which is short-lived and has dermatitis. (N2)

Combination of data allows us to infer that nursing care practices are still concentrated in the postoperative period. They are performed, above all, by nursing technicians, which seems to point to the participation of nurses in meeting specific demands. 
When it is found that there are incomplete nursing records with regard to content and clarity of information, it is understood that these may harm the quality of care and communication among professionals as well as compromising ethical and legal aspects.

\section{Between what is said and what is done: contradiction in nursing practice}

Contradictions were noticed during analysis, when verifying that professionals' statements present in the interviews, many times, differed from the conduct adopted during care actions. Professionals verbalize the need to cut colostomy bag to the size of the stoma diameter; however, when observing care practice, it was found that the professionals did not pay attention to the cut of the bag, which was often larger than the diameter of the stoma.

I take care so that the opening of the bag is not larger, much larger than the stoma, so as not to damage the patient's skin. (NT1)

Another contradiction verified is related to educational guidelines, in which insufficient time becomes a justification for not carrying out educational practices in the preoperative period. However, professionals report that ostomates are well oriented, because in addition to nurses, nursing technicians also assist in the development of skills for self-care.

Generally, when I care for patients in the postoperative period, who didn't have time to advise in the preoperative period, I ask if they have ever manipulated the bag. And from that, I make the guidelines, as they assimilate. (N1)

I think they are well oriented. We try to teach patients during hospitalization. Nursing technicians also teach patients. (N4)

Considering the observations made, it is possible to notice a dissonance between what was observed in loco and what was mentioned in the interviews. Therefore, it is opportune to talk about an episode witnessed during the performance of observations:

The professional, when starting the work shift, goes to the stoma patient to check vital signs, observing the colostomy and questioning its functionality. When questioning the patient about care, he verbalizes not having been informed about the possibility of coming from surgery with the bag and that no one had talked about the subject and neither was he oriented. (Field diary, 03/12/2018)

Fragment from the field diary reveals inconsistency regarding care, explaining the mismatch between statement and practice. These results allow us to infer that professionals' statements often do not correspond to the aspects implemented in care actions; these can show dimensions that are trivialized in the daily nursing work.

\section{Potentials/facilities in caring for ostomates}

When considering the insecurities, difficulties and vulnerabilities experienced by ostomates, professionals recognize that interaction between team, patients and their families is essential to help them understand the new life condition.
[...] I think that care starts with the interaction of professionals with patients and families, making them much more comfortable with that situation. (NT5)

One way to enhance care and service is to achieve greater adherence by family members in care, through interaction, through a more personalized contact with family members. (NT8)

When considering the changes that occur with building the stoma, professionals identify the participation and collaboration of family members as a potentializing factor, which can contribute to the rehabilitation of ostomates. Thus, they recognize that it is essential to demystify care, through a dialogical and simplifying practice, with a view to making it something natural, capable of being carried out in the daily routine at home.

Doing it naturally and with good will. We talk, explaining that it is natural, that little by little they will perform care and self-care. (NT6)

Professionals recognize that factors that contribute to care are related to educational guidelines and patient acceptance, even if this resource is developed by a few members of the nursing team and is directed to the moment before hospital discharge.

The factors that help in care are guidelines, patients and their family in relation to acceptance. (N6)

The concern on the part of the team to guide patients, usually when they discharge patients, is still valid. (NT11)

Another point perceived as a resource that facilitates care is the existence of a specific room for health education, which offers an environment reserved for educational practices, but which is underused.

One of the potentials is this room to develop educational activities, with the availability of dolls and materials that can be used for orientation, but that are not used due to this lack of time. (N1)

Furthermore, professionals recognize that the support offered by co-workers is an essential factor, which allows socializing experiences and facilitating nursing care for ostomates.

As we have several cases, we are always discussing. We are always learning from each other, from the experience of a colleague. (N5)

The data allow us to comprehend that professionals consider, above all, positive aspects that favor care practices related to physiological dimensions. As facilitating resources, interaction of professionals with patients and family members, professional experience, human, physical and material resources stand out as possibilities that favor care.

\section{Difficulties/weaknesses and their impact on nursing care}

The main aspect that makes nursing care difficult is related to building the stoma, which, in its majority, is performed without previous demarcation of the surgical site, being close to the surgical wound, bony prominences or the umbilical scar. Inadequate 
site makes it impossible for colostomy bag to adhere well to the abdominal wall, sometimes reducing its duration.

Patients come here with poor work done in the operating room, because they put a colostomy bag on the side of the surgical wound, but so on the side, that you can't paste the bag and end up placing it on top of the surgical wound. (NT13)

During the observation, it was found that several stomas were poorly located, and that they came, mostly, from elective surgeries, which, a priori, allow surgical demarcation of the site for intestinal loop exteriorization. It is noteworthy that demarcation can be improved with the participation of stomatherapy nurses in the preparatory phase of the future stoma.

Moreover, professionals consider that the stoma characteristic is closely related to the weaknesses experienced in care. Flat osteomas, retracted and supported by a stem, hinder colostomy bag permanence and fixation, challenging the performance of nursing.

The overall difficulty I see in the sector is in relation to the fixation of the bag in patients with more retracted ostomy, in which the surgical technique itself makes it difficult. In other cases, it is the patients who come with that loop that also makes it very difficult, depending on its location and distance from the ostomy. (N4)

Professionals reveal that there is often a lack of adequate materials to provide care, making it necessary to use what is available in the sector, even if this is not the most appropriate choice. This situation associated with limited knowledge related to care, lack of time and the reduced number of employees, given the complexity of the unit, are conditions that converge to the weakening of care practices.

The material part gets in the way. The lack of one or the other impairs care. (NT9)

Sometimes it's because everything is done in a hurry, because we don't have time, and sometimes I think that there is a lack of knowledge of who is doing it. (NT3)

We work at a very busy environment, there are many patients. Often, the orientation part is left to be desired, because the rest you are obliged to do! We will not be able to provide care. (N7)

Another aspect mentioned is related to some mistakes related to cutting, the duration of the collection equipment, and the use of adjuvants to clean the skin and stoma. Situations of this nature denote limitations regarding the technical knowledge of the use of this material.

We don't change much, we change more when it's damaged, or on the fifteenth, twentieth day, more or less. I always try to decrease or increase a little [referring to the cutout of the bag] so as not to always stay in the same space there on the skin. I change to give my skin a break and relief. (NT6)

The data allow to understand and identify the elements that interfere with nursing care practice. Such elements run through the stoma-making and its characteristics, revealing itself in assistance difficulties. In addition to these factors, the professionals report that the lack of adequate materials, limited knowledge, limited time and reduced number of employees are factors that also converge to the fragility of care.

\section{DISCUSSION}

The professionals' knowledge in caring for ostomates is, above all, due to the socialization of knowledge among the members of the nursing team. The results show gaps related to the professional training process, in which, many times, this theme is approached in a superficial and incipient way, being mostly restricted to theory.

Confirming the findings evidenced here, a study carried out with nursing professionals working in a hospital service in direct care for ostomates, revealed that professional training in this specific area is comprehensive. Thus, it occurs with few experiences of care assistance, and the knowledge acquired comes, mostly, from the practices performed in their workplace ${ }^{(5)}$.

Capacity building and training, as well as specialization courses and internet consultations, enable professionals to develop skills for care, updating knowledge and an opportunity to answer questions. The incentive and support of institutions, in order to offer possibilities for professionals to seek updating and qualification, through permanent health education, has been presented as a perspective to improve access to theoretical and scientific knowledge and transform nursing practice. Permanent health education promotes learning and enables professional development and qualification ${ }^{(9)}$.

Regarding the practice of nursing in caring for ostomates, this includes the theoretical and scientific knowledge that guide care, intending to achieve physical and psycho-emotional recovery. From this perspective, nursing care is based on interventions carried out by professionals in order to assist, support and enable people to achieve their well-being ${ }^{(3)}$. However, when professionals centralize care in physiological aspects, people start to be assisted in an unarticulated way. Care actions are directed to meet, primarily, the demands of the stoma, without considering their subjective needs, with no space to promote health education activities and the valorization of being ${ }^{(2)}$.

In this study, it was noticed that the nursing team sometimes does not adequately record care in the patients'medical records. It is known, however, that it is an ethical and legal responsibility of professionals to keep the notes regarding care updated, and they must be imbued with authenticity and veracity, in order to enable continuity of care ${ }^{(10)}$.

A study that aimed to analyze the content of nursing records in the medical records of patients in two hospitals in Maceió, found that the recorded data were insufficient; and, in some cases, nonexistent and that patients as the focus of care did not appear in the nursing records. In this regard, they did not portray the reality of patients and care, and assistance procedures performed by technicians were mostly recorded $^{(11)}$.

The presence of nurses in care is limited to changes or difficulties identified by nursing technicians. Sometimes, there is no significant involvement in the other care actions, nor in the nursing records. These data reveal aspects of the invisibility of this professional in caring for ostomates, and their participation is limited to curative practices.

Nurses have technical, scientific and human competence to act in care, and should not reduce their participation in curative and assistance actions, but being promoters of comprehensive and qualified 
care. Therefore, nurses are committed to planning, implementing and assesing care in a systematic and individualized way ${ }^{(12)}$, being essential for the rehabilitation and autonomy of ostomates ${ }^{(13)}$.

When following the nursing care on the spot, there were sometimes contradictions between what was mentioned by professionals and practices performed. A study developed with nurses working in a Rehabilitation Center in the city of Rio de Janeiro aimed to analyze the educational nursing actions carried out for ostomates; and there were contradictions related to what nurses verbalize in the interview, with what was observed in the routine of nursing consultations. The results obtained in the present research are reinforced by the information identified in this study, allowing to infer that the professionals' statement, mostly, disagrees with practical care ${ }^{(14)}$.

Despite the dissonance between what is said and what is done by professionals in care, there are positive factors associated with care practice. Such factors strengthen and improve the nursing care process. The interaction between the different parties involved in care; family participation during hospitalization; educational guidelines; and the room for health education actions are facilitating resources that assist in acceptance and adaptation.

From this perspective, nursing acts as a transformative agent of care when intervening in emerging problems with building stoma and implementing actions that facilitate the transition process experienced by these people ${ }^{(11,15)}$. In addition to physical and technological resources, professionals identify in the nursing team and technical advisory groups a "society" of cooperation that, when sharing experiences, constitutes an element that enhances care, reinforcing the relevance of teamwork ${ }^{(16)}$.

Bonding, communication and respect for the other generate recognition and appreciation, culminating in the constitution of teamwork. These factors are associated with the professionals' working time and shared experiences. Availability to help the colleague is an opportunity to build consensus on care, as well as a way to complement the technical dimensions of care ${ }^{(6)}$.

Among the difficulties experienced in daily work, inadequate preparation and characteristics of stoma stand out. According to the Charter of Ostomates Rights, the ostomate who will undergo surgery has the right to receive specialized care, including place demarcation ${ }^{(17)}$. Such actions make it possible to ensure the good construction and adequate location of the stoma, in order to favor care and self-care ${ }^{(17-18)}$.

Therefore, demarcation and use of an appropriate surgical technique contribute to prevent or minimize immediate and late postoperative complications; and contributes greatly to the autonomy of ostomates, as well as the effectiveness of nursing care ${ }^{(19-20)}$. This condition of the surgical technique associated with limited knowledge of stoma management contributes to the fragility of nursing care.

Insufficient and superficial knowledge of professionals denotes little theoretical-scientific basis, restricting care to physiological recovery and performance of basic actions related to stoma maintenance. However, acquiring scientific and practical domains is essential to act in a way that promotes adaptation and safety of ostomates ${ }^{(21)}$.

From this perspective, for nursing care to be comprehensive, it is important to merge efforts to contemplate the psychosocial, spiritual and labor dimensions, in order to qualify care ${ }^{(22)}$. Thus, the relevance of the nursing team in the adaptive process of ostomates must be considered. The gradual and constant improvement of scientific knowledge is an opportunity to train professionals for care ${ }^{(23)}$.

\section{Study limitations}

The limitation of this study is the fact that it was performed in a general surgery unit, which restricts the possibility of generalizing the results to the sample and the context where the investigation was carried out. Nevertheless, the results obtained contribute to validate studies carried out that point out the importance of knowing the perceptions of nursing professionals about their work.

\section{Contributions to nursing and health}

The results confirm aspects described in the nursing literature. It can be stated that it is still relevant to develop studies that explore the reality of care provided to this population, expanding the understanding of aspects that influence the quality of nursing care. It is understood that these studies can contribute to raise awareness and alert nursing professionals to the need to invest in training and in actions that can modify care to people with colostomy bag.

Furthermore, the results reveal the emerging need to develop a specific public policy aimed at this population, in addition to the established in the ordinance, which establishes the care network for people with physical disabilities within SUS (Sistema Único de Saúde - Brazilian Health System). There is a need for specificity of care for ostomates, aiming to meet their health needs continuously and comprehensiveness. With this in mind, it is understood that investigations in other health care settings as well as those that propose educational interventions with the aim of providing health professionals with care for people with colostomy bag may contribute to building knowledge in this field.

\section{FINAL CONSIDERATIONS}

The results refer to the knowledge and care practices performed in hospitals for people with colostomy bag from the perspective of nursing professionals. Thus, it was possible to apprehend the knowledge that guides care, which comes mainly from socialization of practices and information among the team, revealing gaps that still exist in the professional training process.

Likewise, it was identified that the knowledge and practices are mostly directed at the physical and physiological dimensions related to stoma and colostomy bag care, not prioritizing changes related to biopsychosocial aspects. In order for nursing care to transcend biological aspects, it is pertinent to recognize ostomates as complex and unique beings, who experiences a singular experience and which requires a care plan adjusted to their real needs, from the preoperative stage.

Concluding, it is relevant to break the influences of the biomedical model still consolidated in professional training, with a view to organizing theoretical and scientific perspectives that favor the implementation of a new care standard that considers the completeness of subjects involved in nursing care. To that end, it is necessary that professionals are sensitized to understand the changes that come with stoma building, using a sensitive, qualified and empathetic listening that allows the holistic understanding of human beings. 


\section{FUNDING}

The research was carried out with the support of the Coordination for the Improvement of Higher Education Personnel
(Coordenação de Aperfeiçoamento de Pessoal de Nível Superior, abbreviated CAPES) Financing Code 001 and the Scientific Initiation Scholarship Program of the Hospital Universitário de Santa Maria (PROIC-HUSM) by granting a scientific initiation scholarship.

\section{REFERENCES}

1. Waldow VR. Cuidar: uma expressão humanizadora da enfermagem. Petrópolis, Rio de Janeiro: Vozes; 2012. 15-37 p.

2. García-Vera M, Merighi MAB, Conz CA, Silva MH, Jesus MCP, Muñoz-González LA. Primary health care: the experience of nurses. Rev Bras Enferm. 2018;71(Suppl 1):531-7. doi: 10.1590/0034-7167-2016-0244

3. Oliveira LN, Lopes APAT, Decesaro MN. Complete care for the stomized person in primary care - knowledge and nursing activities. Ciênc Cuid Saúde. 2017;16(3)1-8. doi: 10.4025/cienccuidsaude.v16i3.35998

4. Smeltzer SC, Bare BG. Brunner \& Suddarth: tratado de enfermagem médico-cirúrgica. Rio de Janeiro: Guanabara Koogan; 2015.

5. Ardigo FS, Amante LN. Knowledge of the professional about nursing care of people with ostomies and their families. Texto Contexto Enferm. 2013;22(4):1064-71. doi: 10.1590/S0104-07072013000400024

6. Mota MS, Gomes GC, Petuco VM. Repercussions in the living process of people with stomas. Texto Contexto Enferm. 2016;25(1): e1260014. doi:10.1590/0104-070720160001260014

7. Souza MT, Moraes AA, Balbino CM, Silvino ZR, Tavares CMM, Passos JP. Emotional support provided by the nurse to the ostomized patient. Rev Port Enferm Saúde Mental. 2016;(spe4):49-56. doi: 10.19131/rpesm.0141

8. Creswell JW. Investigação qualitativa e projeto de pesquisa. Porto Alegre: Penso; 2014. 147 p.

9. Flores GE, Oliveira DLL, Zocche DAA. Permanent education in the hospital context: the experience that brings new meaning to nursing care. Trab Educ Saúde. 2016;14(2):487-504. doi: 10.1590/1981-7746-sip00118

10. Conselho Federal de Enfermagem. Resolução n 564 de 06 de novembro de 2017. Código de Ética dos Profissionais de Enfermagem [Internet]. Brasília: COFEN; 2017 [cited 2019 Jul 17]. Available from: http://www.cofen.gov.br/resolucao-cofen-no-5642017_59145.html

11. Silva TG, Santos RM, Crispim LMC, Almeida LMWS. Conteúdo dos registros de enfermagem em hospitais: contribuições para o desenvolvimento do processo de enfermagem. Enferm Foco. 2016;7(1):24-7. doi: 10.21675/2357-707X.2016.v7.n1.679

12. Vasconcellos FM, Xavier ZDM. The nurse in the customer assistance colostomy based Orem of theory. Rev Recien. 2015;5(2):25-37. doi: 10.24276/rrecien2358-3088.2015.5.14.25-37

13. Farias DLS, Nery RNB, Santana ME. O enfermeiro como educador em saúde da pessoa estomizada com câncer colorretal. Enferm Foco. 2019;10(1):35-39. doi: 10.21675/2357-707X.2019.v10.n1.1486

14. Maurício VC, Souza NVDO, Costa CCP, Dias MO. The view of nurses about educational practices targeted at people with a stoma. EsC Anna Nery. 2017;21(4):1-8. doi: 10.1590/2177-9465-ean-2017-0003.

15. Mota MS, Gomes GC, Petuco VM, Heck RM, Barros EJL, Gomes VLO. Facilitators of the transition process for the self-care of the person with stoma: subsidies for nursing. Rev Esc Enferm USP. 2015;49(1):82-8. doi: 10.1590/S0080-623420150000100011

16. Sangiovo S, Andrade A, Arboit EL, Consentino SF. Strengths and weaknesses of a team of surgical nursing center. Rev Espaço Ciên Saúde [Internet]. 2015 [cited 2019 Jul 23];3(1):1-14. Available from: http://revistaeletronica.unicruz.edu.br/index.php/enfermagem/article/view/5304/938

17. International Ostomy Association (IOA). Declaração Internacional dos Direitos dos Ostomizados. [Internet]. 1993; Revised by World Council 2007. [cited 2019 Jul 23]. Available from: http://www.ostomyinternational.org/about-us/charter.html

18. Perissotto S, Breder JSC, Zulian LR, Oliveira VX de, Silveira NI, Alexandre NMC. Nursing actions for prevention and treatment of complications in intestinal stomies. Rev Estima. 2019;17(e0519)1-8. doi: 10.30886/estima.v17.638_PT

19. Cesaretti IUR, Silveira NI, Ricarte MC, D'Ávila ES. Tecnologia no cuidar de pessoas com estomia: a questão dos equipamentos e adjuvantes. In: Santos VLCG, Cesaretti IUR. Assistência em Estomaterapia: cuidando de pessoas com estomia. São Paulo: Editora Atheneu; 2015. p. 284.

20. Person B, Ifargan R, Lachter J, Duek S, Kluger Y, Assalia A. The impact of preoperative stoma site making on the incidence of complications, quality of life and patient's independence. Dis Colon Rectum. 2012;55(7):783-7. doi: 10.1097/DCR.0b013e31825763fo.

21. Simon BS, Budó MLD, Schimith MD, Leal TC, Silva MM, Wunsch S, et al. Professional attention to the families of people with elimination stoma: the duality experienced. Rev Estima. 2018;16(1918):1-9. doi: 10.30886/estima.v16.457

22. Grant M, Mccorkle R, Hornbrook MC, Wendel CS, Krouse R. Development of a chronic care ostomy self-management program. J Cancer Educ. 2013;28(1):70-8. doi: 10.1007/s13187-012-0433-1

23. Medeiros LP, Silva IP, Lucena SKP, Sena JF, Mesquita EKS, Oliveira DMS, et al. Nursing intervention actives "care for ostomy". Rev Enferm UFPE. 2017;11(12):5417-26. doi: 10.5205/1981-8963-v11i12a22899p5417-5426-2017 